\title{
IGFBP1 Is a Predictive Factor for Haematogenous Metastasis in Patients With Gastric Cancer
}

\author{
YUYA SATO $^{1}$, MIKITO INOKUCHI $^{1}$, YOKO TAKAGI $^{2}$ and KAZUYUKI KOJIMA ${ }^{3}$ \\ ${ }^{1}$ Department of Gastric Surgery, Tokyo Medical and Dental University, Tokyo, Japan; \\ ${ }^{2}$ Division of Specialized Surgeries, Tokyo Medical and Dental University, Tokyo, Japan; \\ ${ }^{3}$ First Department of Surgery, Dokkyo Medical University, Tochigi, Japan
}

\begin{abstract}
Background/Aim: The clinicopathological significance and prognostic value of insulin-like growth factor binding protein 1 (IGFBP1) in gastric cancer have not been investigated to date. This study aimed to investigate the relationship of IGFBPI expression with clinicopathological variables and prognosis. Materials and Methods: The correlation of IGFBPI expression with the clinicopathological factors and the correlation of clinicopathogical factors with haematogenous metastasis in 219 gastric cancer patients who underwent surgery was examined. Results: High IGFBPI expression was significantly associated with a poorer diseasespecific survival $(p<0.001)$ and relapse-free survival $(p<0.001)$ in univariable analysis although IGFBPI was not an independent prognostic factor. High IGFBPI expression was the only independent risk factor of haematogenous metastasis. Conclusion: High IGFBPI expression was associated with haematogenous metastasis and poor survival. IGFBPI might become a new prognostic factor and a target of molecular targeted therapy of gastric cancer.
\end{abstract}

Gastric cancer is the fifth most common type of malignant tumour worldwide. An estimated one million new cases are diagnosed every year, resulting in about 700,000 annual deaths (1). Surgical resection and subsequent adjuvant chemotherapy have become the standard treatment for most patients with clinically diagnosed locally advanced gastric cancer (2). Although chemotherapy including pre- and postoperative chemotherapy has been developed to prevent and control metastatic recurrence that is strongly related to gastric cancer mortality, the prognosis in patients with advanced tumour

Correspondence to: Mikito Inokuchi, MD, Department of Gastric Surgery, Tokyo Medical and Dental University, 1-5-45, Yushima, Bunkyo-ku, Tokyo 113-8530, Japan. Tel: +81 358035261, Fax: +81 358030139, e-mail: m-inokuchi.srg2@tmd.ac.jp

Key Words: Gastric cancer, IGFBP1, immunohistochemistry, tumour progression, angiogenesis, hematogenous metastasis. remains unsatisfactory $(3,4)$. Therefore, it is crucial to identify reliable prognosis markers that will allow better management and identification of potential therapeutic targets.

The insulin-like growth factor (IGF) axis plays a key role in the growth, differentiation and proliferation of mammalian cells or angiogenic activities and consists of two growth factors (IGF-I and IGF-II), their receptors (IGF-IR and IGFIIR) and a group of insulin-like growth factor binding proteins (IGFBPs). IGFBPs consist of 7 well-characterized members (IGFBP1-7) (5). Matsubara et al. have reported that IGF-IR expression in gastric cancer specimens was a significant predictor of poor survival in patients with advanced gastric cancer (6). Anti-IGF-IR strategies may prove valuable in such patients. The actions of IGFs may be modulated by the IGFBPs in a positive or negative way, depending on the tissue type and the physiological/ pathological status (7). In most circumstances, they inhibit IGF actions by preventing the binding to IGF receptors; however, they may also potentiate their actions (8). In gastric cancer, clinical impacts of IGFBP expression have been investigated for few subtypes of the IGFBPs family. The clinicopathological significance of $\operatorname{IGFBP2}(9,10)$ and IGFBBP7 $(11,12)$ in gastric cancer has already been reported, and IGFBP2 and IGFBP7 might become new prognostic factors in gastric cancer patients in the future.

In contrast, the clinicopathological significance and prognostic value of IGFBP1 in gastric cancer have not been investigated previously. IGFBP1 expression has been documented to be both, positively and negatively correlated with cancer risk, tumour progression and prognosis in colorectal cancer (13), breast cancer (14) and hepatocellular cancer (15). In the present study, the relationship of IGFBP1 expression with clinicopathological variables and prognosis in gastric cancer was examined.

\section{Patients and Methods}

Patients. The study group comprised 219 patients with gastric cancer who underwent surgery from January 2003 to December 2007 at the Department of Gastric Surgery, Tokyo Medical and Dental University. Each tumour was classified as per the tumour- 
node-metastasis (TNM) system recommended by the International Union against Cancer.

Patient characteristics are shown in Table I. Of the 219 patients, 165 were men and 54 were women. Their median age was 66 years (range=21-92 years). All patients were evaluated for recurrent disease using diagnostic imaging (computed tomography, ultrasonography, magnetic resonance imaging, and endoscopy) every 3-6 months. Patients with distant metastatic or recurrent disease received chemotherapy with S-1 alone or combined chemotherapy. Nineteen patients $(9 \%)$ received adjuvant chemotherapy with S-1 after radical resection. All the patients were followed up until January 2013. The median follow-up duration was 60 months (range=3-111 months). Among all the patients, 18 had haematogenous metastasis (simultaneous metastasis: 1 patient, metachronous metastasis: 17 patients). Peritoneal metastasis was present in 43 patients (19.6\%), and distant lymph node metastasis was observed in 32 patients $(14.6 \%)$. Metastases to the liver, lung, brain and bone were defined as haematogenous metastases. Total $77(35 \%)$ patients died, 67 (31\%) had recurrent disease and $9(4 \%)$ died because of other causes.

Human rights statement and informed consent. All procedures followed were in accordance with the ethical standards of the institutional review board of Tokyo Medical and Dental University (approval no. 831) and national ethical standards of the responsible committee on human experimentation and with the Helsinki Declaration of 1964, and later versions. Informed consent or a substitute for it was obtained from all the patients prior to their inclusion in the study.

Immunohistochemical analysis of IGFBP1 or IGFBP2. Immunohistochemical staining was performed using a peroxidase-labelled polymer conjugated to secondary antibodies (Histofine Simple Stain MAX PO (MULTI), Nichirei Co., Tokyo, Japan). Polyclonal rabbit antibodies against IGFBP1 (ab111203) and IGFBP2 (ab109284) were purchased from Abcam (Cambridge, UK). All the available H\&E-stained slides of the surgical specimens were reviewed. For each case, representative paraffin blocks were selected for immunohistochemical studies. Four-micrometre-thick sections were cut from each formalin-fixed, paraffin-embedded tissue block. After deparaffinisation and rehydration, antigen retrieval treatment was administered at $400 \mathrm{~W}$ (microwave) for $15 \mathrm{~min}$ in 10-mmoll sodium citrate buffer ( $\mathrm{pH} 9.0)$, followed by treatment with $3 \%$ hydrogen peroxide for 15 min to quench the endogenous peroxidase activity.

The slides were incubated with the primary anti-IGFBP1 antibody $(1: 100)$ or anti-IGFBP2 antibody $(1: 100)$ overnight at $4^{\circ} \mathrm{C}$. Immunodetection was performed using the conventional streptavidin-biotin method with peroxidase-labelled SAB-PO kits (Nichirei Co, Tokyo, Japan). Diaminobenzidine substrate was used for colour development. The slides were counterstained with $1 \%$ Mayer's haematoxylin.

Interpretation of the immunostaining results. IGFBP1 and IGFBP2 expressions in the cytoplasm were evaluated using a scoring method based on the staining extent and staining intensity. The staining extent (positive frequency) was classified into four grades as per the percentage of stained tumour cells: 1 for $<25 \%, 2$ for $25 \%$ to $<50 \%$, 3 for $50 \%$ to $<75 \%$ and 4 for $\geq 75 \%$ stained cells. The staining intensity was scored as per the following three grades: 0 (no staining $[-]$ or weakly positive $[ \pm]$ ), 1 (moderately positive $[+]$ ) and 2 (strongly positive [++]) (Figures 1 and 2). Composite scores were multiplied to
Table I. Patient characteristics.

\begin{tabular}{ll}
\hline & Entire cohort (n=219), $\mathrm{n}(\%)$ \\
\hline Gender & \\
Male & $165(75 \%)$ \\
Female & $54(25 \%)$ \\
Age (year) (median [range]) & $66.0(21-92)$ \\
Main tumour location & \\
U & $46(21 \%)$ \\
ML & $173(79 \%)$ \\
Histopathology & \\
Differentiated & $115(52 \%)$ \\
Undifferentiated & $104(48 \%)$ \\
Depth of invasion & \\
T1 & $86(39 \%)$ \\
T2 & $29(13 \%)$ \\
T3 & $38(17 \%)$ \\
T4 & $66(30 \%)$ \\
Lymph node metastasis & \\
Positive & $107(49 \%)$ \\
Negative & $112(51 \%)$ \\
Stage classification & \\
Stage I & $104(48 \%)$ \\
Stage II & $35(16 \%)$ \\
Stage III & $62(28 \%)$ \\
Stage IV & $18(8 \%)$ \\
\hline
\end{tabular}

U: Upper; ML: middle or lower.

produce a weighted score for each case (ranging from 1-6). For the statistical analyses, composite scores of $\geq 3$ were defined as high expression, and scores $<3$ were considered to indicate low expression. Staining was assessed by three separate observers (YS, YT and MI) who were blinded to the patient data. Any disagreements among the three investigators were resolved by reassessment and consensus.

Statistical analyses. The $\chi^{2}$ test was used to test the possible associations of IGFBP1 and IGFBP2 expression with clinicopathological variables. Kaplan-Meier curves were plotted to assess the effect of IGFBP1 and IGFBP2 expression on diseasespecific survival (DSS). Different DSS curves were compared using the log-rank test. Multivariable proportional hazards Cox regression models were used to assess the prognostic significance of IGFBP1 and the factors associated with DSS. Any association with a $p$-value $<0.10$ on univariable analysis was included in the multivariable analysis. All $p$-values $<0.05$ were considered to indicate statistical significance. Statistical analyses were performed using IBM SPSS Statistics V.22 software (IBM, Armonk, NY, USA).

\section{Results}

Correlation between IGFBPI protein expression and $I G F B P 2$ protein expression. Among all patients, the numbers of patients with IGFBP1 high/IGFBP2 high, IGFBP1 high/IGFBP2 low, IGFBP1 low/IGFBP2 high and IGFBP1 low/IGFBP2 low were 41, 41, 25 and 112, respectively. IGFBP1 protein expression and IGFBP2 protein expression were positively correlated $(p<0.001)$. 

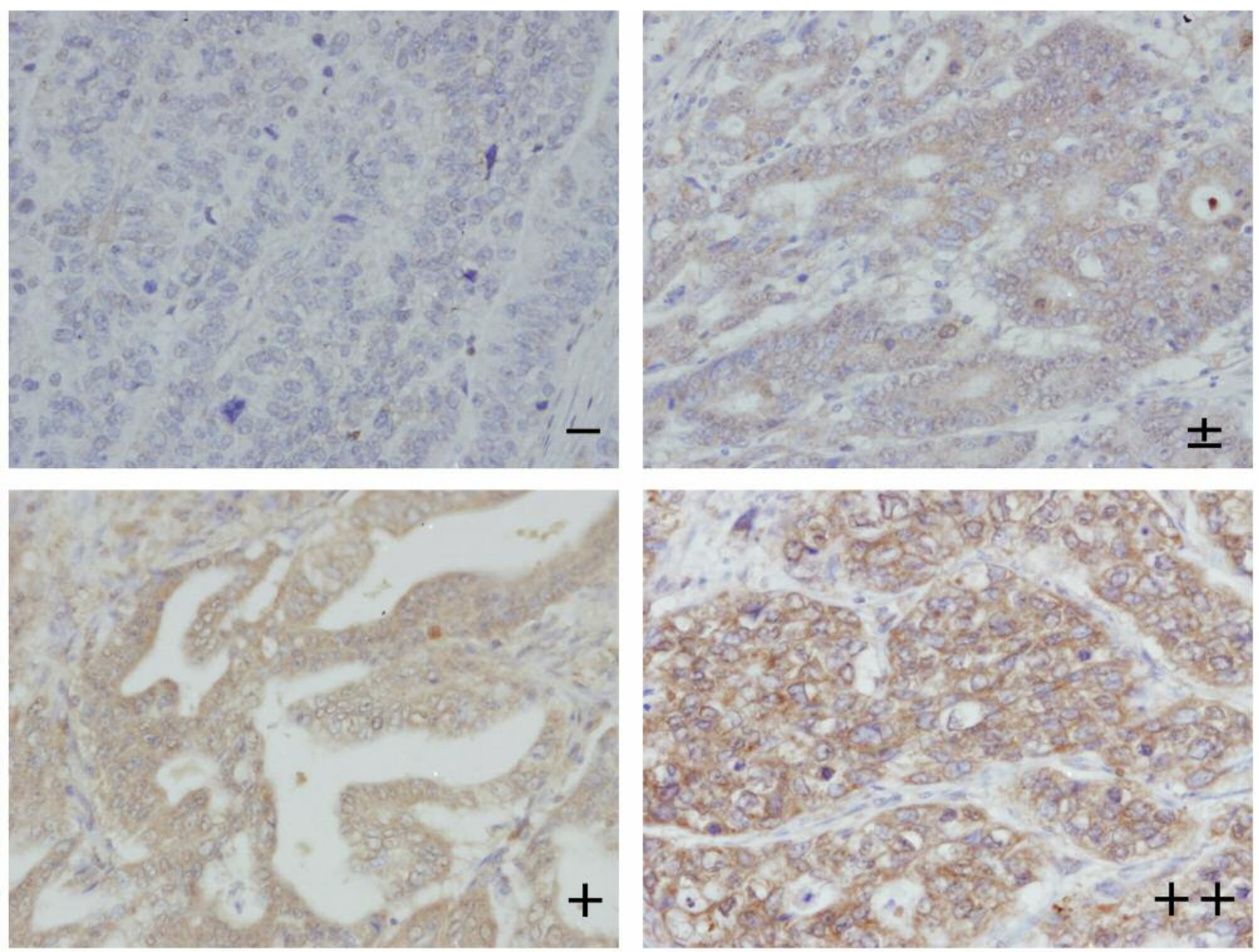

Figure 1. Representative immunostaining of insulin-like growth factor binding protein-1 (IGFBP1) in gastric cancer. [-] No staining; [ \pm ] weakly positive; [+] moderately positive; [++] strongly positive.

Correlation between IGFBP1/IGFBP2 protein expression and clinicopathological parameters. The correlation between IGFBP1/IGFBP2 protein expression and clinicopathological parameters is shown in Table II. The IGFBP1 expression was positively associated with the depth of invasion ( $\mathrm{T} 1 \mathrm{vs}$. T24, $p<0.001$ ), lymph node (LN) metastasis (NO vs. N1-3, $p<0.001$ ), lymphatic invasion (negative $v s$. positive, $p<0.001$ ), venous invasion (negative $v s$. positive, $p<0.001$ ) and pathological stage (Stage I $v s$. II-IV, $p<0.001$ ).

IGFBP2 expression was associated with Lauren Classification (Intestinal $v s$. Diffuse, $p<0.001$ ) and was positively associated with the pathological stage (Stage I $v s$. II-IV, $p<0.001)$.

Correlation between IGFBP1/IGFBP2 protein expression and DSS. The correlation of clinicopathological factors with DSS is shown in Table III. High IGFBP1 expression was significantly associated with a poorer DSS $(p<0.001)$. The 5 -year DSS of patients with high IGFBP1 expression was $59.1 \%$, while that of those with low IGFBP1 expression was $80.0 \%$ (Figure 3A). The 5-year DSS of patients with high and low IGFBP2 was $71.5 \%$ and $73.0 \%$, respectively, showing no significant difference $(p=0.667)$ (Figure 3B). Tumour location (upper third of the stomach), Lauren Classification (diffuse type), depth of invasion (T2-4) and positive lymph node metastases were significantly associated with a poorer DSS in a univariable analysis. An adjusted multivariable analysis of the clinicopathological features affecting DSS indicated that IGFBP1 expression was not an independent prognostic factor $(\mathrm{HR}=1.2 ; 95 \% \mathrm{CI}=0.74-2.1$; $p=0.42$ )] although depth of invasion and lymph node metastases were identified as independent prognostic factors $(\mathrm{HR}=10.7 ; 95 \% \mathrm{CI}=2.5-45.8 ; \quad p=0.001$ and $\mathrm{HR}=6.0$; $95 \% \mathrm{CI}=2.5-13.4 ; p<0.001$; respectively; Table II). 

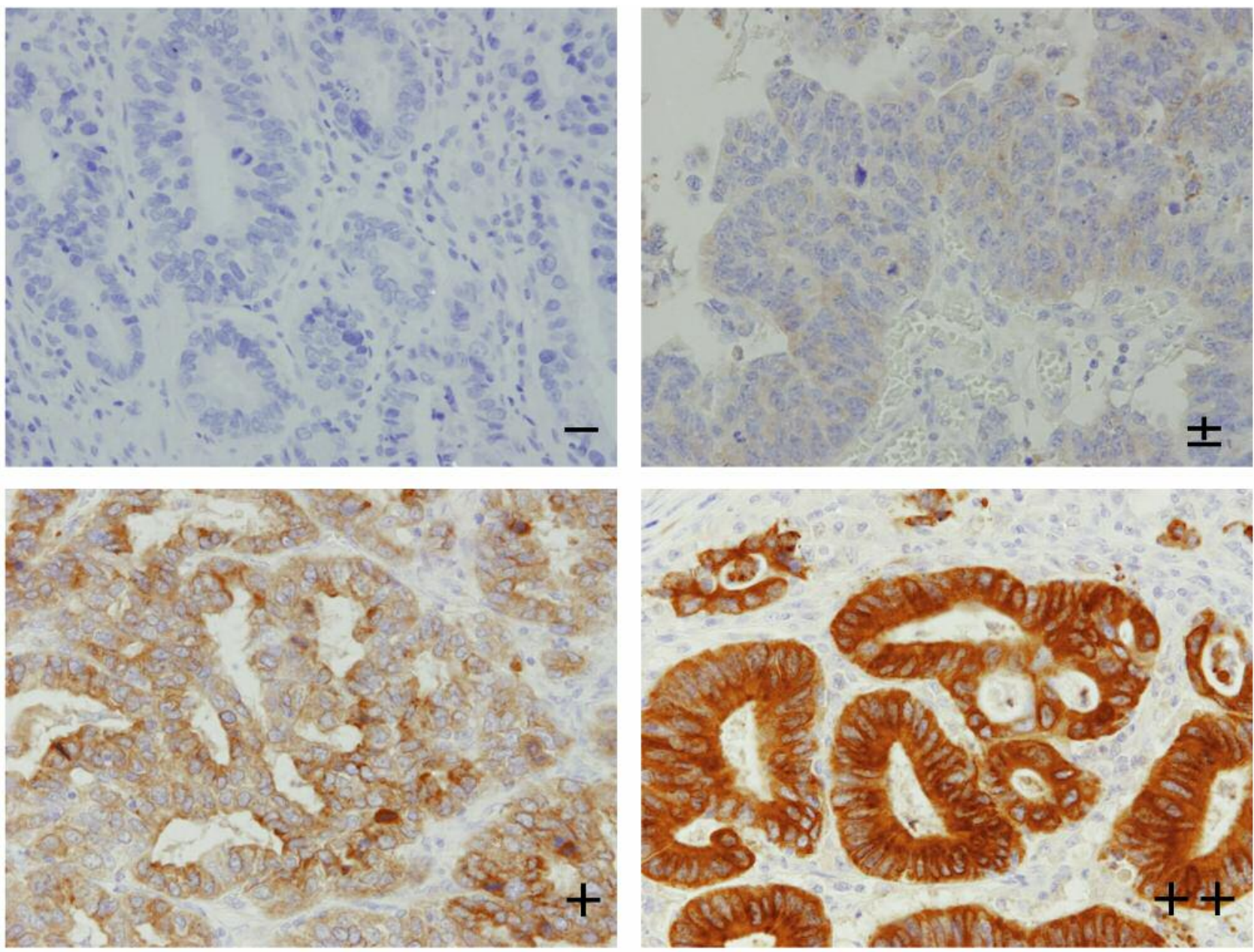

Figure 2. Representative immunostaining of insulin-like growth factor binding protein-2 (IGFBP2) in gastric cancer. [-] No staining; [ \pm ] weakly positive; [+] moderately positive; [++] strongly positive.

In a total of 217 patients who underwent radical gastrectomy without macroscopically residual tumour; high IGFBP1 expression was also significantly associated with a poorer RFS $(p<0.001)$. The 5-year RFS of patients with high and low IGFBP1 expressions was $51.9 \%$ and $79.1 \%$, respectively (Figure 4A). The 5-year RFS of patients with high and low IGFBP2 expressions was $69.9 \%$ and $68.9 \%$, respectively $(p=0.925)$ (Figure $4 \mathrm{~B})$.

Correlation between clinicopathogical factors and haematogenous metastasis. The correlation of the clinicopathogical factors and haematogenous metastasis is shown in Table IV. In univariate analysis, the depth of invasion (T24, $p=0.002)$, LN metastasis (N1-3, $p=0.013$ ), lymphatic invasion (positive, $p=0.008$ ), pathological stage (Stage II-IV, $p=0.006$ ) and IGFBP1 expression (positive, $p<0.001$ ) were significantly correlated with haematogenous metastasis.
Although IGFBP2 expression tended to be associated with haematogenous metastasis, no significant difference was seen between IGFBP2 high and low patients $(p=0.064)$. In multivariate analysis, only IGFBP1 expression was found to be correlated with haematogenous metastasis.

\section{Discussion}

Our results showed that high IGFBP1 expression was significantly correlated with haematogenous metastasis and poor survival in patients with gastric cancer who underwent gastrectomy. To our knowledge, this is the first study that investigated the relationship of IGFBP1 expression with clinicopathological variables and prognosis in gastric cancer.

Few studies have evaluated the association of IGFBP1 expression with clinicopathological factors in solid cancer. 
Table II. Correlation between IGFBP1/IGFBP2 protein expression and clinicopathological parameters.

\begin{tabular}{|c|c|c|c|c|c|c|c|c|}
\hline & \multicolumn{4}{|c|}{ IGFBP1 expression } & \multicolumn{4}{|c|}{ IGFBP2 expression } \\
\hline & Low & High & Proportion & $p$-Value & Low & High & Proportion & $p$-Value \\
\hline \multicolumn{9}{|l|}{ Age (years) } \\
\hline$\geq 65$ & 67 & 49 & $42.2 \%$ & 0.094 & 78 & 38 & $32.8 \%$ & 0.381 \\
\hline$<65$ & 71 & 32 & $31.1 \%$ & & 75 & 28 & $27.2 \%$ & \\
\hline \multicolumn{9}{|l|}{ Gender } \\
\hline Male & 99 & 66 & $40.0 \%$ & 0.143 & 112 & 53 & $32.1 \%$ & 0.308 \\
\hline Female & 39 & 15 & $27.8 \%$ & & 41 & 13 & $24.1 \%$ & \\
\hline \multicolumn{9}{|l|}{ Lauren Classification } \\
\hline Intestinal & 60 & 44 & $42.3 \%$ & 0.126 & 61 & 43 & $41.3 \%$ & $<0.001$ \\
\hline Diffuse & 78 & 37 & $32.2 \%$ & & 92 & 23 & $20.0 \%$ & \\
\hline \multicolumn{9}{|l|}{ Depth of invasion } \\
\hline $\mathrm{T} 1$ & 74 & 12 & $14.0 \%$ & $<0.001$ & 66 & 20 & $23.3 \%$ & 0.097 \\
\hline $\mathrm{T} 2,3,4$ & 64 & 69 & $51.9 \%$ & & 87 & 46 & $34.6 \%$ & \\
\hline \multicolumn{9}{|l|}{ LN metastasis } \\
\hline Negative (N0) & 84 & 28 & $25.0 \%$ & $<0.001$ & 83 & 29 & $25.9 \%$ & 0.186 \\
\hline Positive $(\mathrm{N} 1,2,3)$ & 54 & 53 & $49.5 \%$ & & 70 & 37 & $34.6 \%$ & \\
\hline \multicolumn{9}{|l|}{ Lymphatic invasion } \\
\hline Negative & 58 & 15 & $20.5 \%$ & $<0.001$ & 54 & 19 & $26.0 \%$ & 0.355 \\
\hline Positive & 80 & 66 & $45.2 \%$ & & 100 & 48 & $32.4 \%$ & \\
\hline \multicolumn{9}{|l|}{ Venous invasion } \\
\hline Negative & 64 & 15 & $19.0 \%$ & $<0.001$ & 59 & 21 & $26.3 \%$ & 0.363 \\
\hline Positive & 74 & 66 & $47.1 \%$ & & 95 & 46 & $32.6 \%$ & \\
\hline \multicolumn{9}{|l|}{ Stage } \\
\hline I & 83 & 21 & $20.2 \%$ & $<0.001$ & 80 & 24 & $23.1 \%$ & 0.039 \\
\hline II/III/IV & 55 & 60 & $52.2 \%$ & & 73 & 42 & $36.5 \%$ & \\
\hline
\end{tabular}

LN: Lymph node.

IGFBP1 expression has been reported to have positive or negative correlation with cancer risk in some types of cancer (13-15). Luo C et al. have investigated the expression pattern of IGFBP-1 of gastric adenocarcinoma infected with H. pylori and evaluated its role in the process of gastric cancer migration (16). The expression and release of IGFBP1 were increased, with enhanced expression being associated with the migration ability of cancer cells in gastric cancer infected with $H$. pylori. They also reported that IGFBP-1 could modulate the MMP-9 expression and be involved in the process of $H$. pylori-induced MMP-9 expression, suggesting that IGFBP-1 may be a tumour-suppressor gene in the process of $H$. pylori-induced gastric cancer. However, this was an in vitro study using a cell line and limited to gastric cancer infected with H. pylori. Based on our results, IGFBP1 was suggested to be a tumour promoter that accelerated haematogenous metastasis and led to poor survival in gastric cancer. These findings suggest that IGFBP1 may potentially serve as a target of molecular targeted therapy in gastric cancer. In clinical practice, an anti-IGFBP1 drug may prevent haematogenous metastasis and improve survival in gastric cancer patients with high IGFBP1 protein expression.
We speculate that in gastric cancer patients, haematogenous metastasis may be promoted by the angiogenic action of IGFBP1 via both, IGF-dependent and IGF-independent pathways. In vitro studies have showed that IGFBP1 potentiates the action of IGFs, thereby increasing the migration of the endothelial cells in microvessels and large vessels (17, 18). Haematogenous metastasis may also be promoted by several IGF-independent pathways of IGFBP1 that reportedly accelerate angiogenesis (19-21).

In this study, IGFBP1 was a significant independent risk factor of haematogenous metastasis although IGFBP1 was not significantly correlated with DSS, based on multivariate analysis. This may be because haematogenous metastasis was not a major cause of cancer-related death. In this study, 68 patients died because of gastric cancer. Haematogenous metastasis was present only in 18 of these patients $(15 \%)$. However, peritoneal metastasis was observed in 41 patients $(65 \%)$ and was considered the main cause of cancer-caused death in this study.

Based on the present results, IGFBP2 was not significantly related to survival, although IGFBP2 is reported to have a positive relationship with clinicopathological factors in gastric cancer. Shi et al. have reported that the expression of IGFBP2 in gastric cancer was higher than that 
Table III. Prognostic factors for disease-specific survival (DSS) in univariate and multivariate Cox proportional-hazards regression models.

\begin{tabular}{|c|c|c|c|c|c|}
\hline & \multicolumn{2}{|c|}{ Univariate (Log-rank) } & \multicolumn{3}{|c|}{ Multivariate (Cox regression) } \\
\hline & 5-years DSS & $p$-Value & HR & $95 \%$ CI & $p$-Value \\
\hline \multicolumn{6}{|l|}{ Age (years) } \\
\hline$\geq 65$ & $68.2 \%$ & 0.193 & & & \\
\hline$<65$ & $74.4 \%$ & & & & \\
\hline \multicolumn{6}{|l|}{ Gender } \\
\hline Female & $72.2 \%$ & 0.907 & & & \\
\hline Male & $70.7 \%$ & & & & \\
\hline \multicolumn{6}{|l|}{ Location } \\
\hline ML & $75.7 \%$ & 0.004 & & & \\
\hline $\mathrm{U}$ & $54.1 \%$ & & 1.53 & $0.91-2.56$ & 0.10 \\
\hline \multicolumn{6}{|l|}{ Lauren Classification } \\
\hline Intestinal & $80.6 \%$ & 0.005 & & & \\
\hline Diffuse & $62.5 \%$ & & 1.43 & $0.84-2.42$ & 0.19 \\
\hline \multicolumn{6}{|l|}{ Depth of invasion } \\
\hline $\mathrm{T} 1$ & $97.7 \%$ & $<0.001$ & & & \\
\hline $\mathrm{T} 2 / 3 / 4 /$ & $53.7 \%$ & & 10.73 & $2.51-45.82$ & 0.001 \\
\hline \multicolumn{6}{|l|}{$\mathrm{LN}$ metastasis } \\
\hline Negative (N0) & $94.6 \%$ & $<0.001$ & & & \\
\hline Positive (N1/2/3) & $46.1 \%$ & & 5.95 & $2.46-13.37$ & $<0.001$ \\
\hline \multicolumn{6}{|l|}{ IGFBP1 } \\
\hline Low & $80.0 \%$ & $<0.001$ & & & \\
\hline High & $59.1 \%$ & & 1.23 & $0.74-2.05$ & 0.42 \\
\hline \multicolumn{6}{|l|}{ IGFBP2 } \\
\hline Low & $73.0 \%$ & 0.667 & & & \\
\hline High & $71.5 \%$ & & & & \\
\hline
\end{tabular}

ML: Middle or lower; U: upper; LN: lymph node; DSS: disease-specific survival; HR: hazard ratio; CI: confidence interval.

in the normal gastric mucosa (9). Zhang et al. have reported a positive correlation between IGFBP2 expression and the depth of penetration, lymph node metastasis and clinical stage in gastric cancer (10). In some other cancers, it is thought that IGFBP2 promotes cancer progression (8). IGFBP2 induces cancer cell proliferation, survival and migration/invasion via mechanisms involving integrins and other pathways, including the Wnt pathway (22-24). In our study, IGFBP2 expression was more common in intestinal cancer and higher stage cancer and tended to be positively associated with haematogenous metastasis. However, there was no positive relationship between IGFBP2 expression and prognosis. Our sample size may have been insufficient to indicate a positive influence of IGFBP2 expression on prognosis. Our results indicate that the influence of IGFBP1 on prognosis will be more significant than that of IGFBP2.

This study has certain limitations. First, the mechanism by which IGFBP1 promoted haematogenous metastasis was not revealed. Further investigations, such as functional analyses using cell lines, are warranted to obtain an understanding of the biological function of IGFBP1 in gastric cancer. Second, the relation between the combination of expression of IGFBP subtypes and clinicopathological factors was not investigated. We speculate that IGFBP family members may interact with each other because IGF-independent actions of IGFBPs have also been described recently.

In conclusion, high IGFBP1 expression is associated with haematogenous metastasis and poor survival in patients with gastric cancer. IGFBP1 might become a new prognostic factor and a target of molecular targeted therapy for gastric cancer.

\section{Conflicts of Interest}

The Authors declare that they have no conflicts of interests.

\section{Authors' Contributions}

Study concepts: YS, MI; Study design: YS, MI, YT; Conducting the study: YS, MI, YT; Immunohistochemistry and analysis: YS, MI, YT; Data analysis and interpretation: YS, MI, YT; Statistical analysis: YS, MI; Manuscript preparation: YS, MI; Manuscript review and revise: YT, KK.

\section{References}

1 Ferlay J, Soerjomataram I, Dikshit R, Eser S, Mathers C, Rebelo M, Parkin DM, Forman D and Bray F: Cancer incidence and mortality worldwide: Sources, methods and major patterns in globocan 2012. Int J Cancer 136(5): E359-386, 2015. PMID: 25220842. DOI: $10.1002 / \mathrm{ijc} .29210$ 

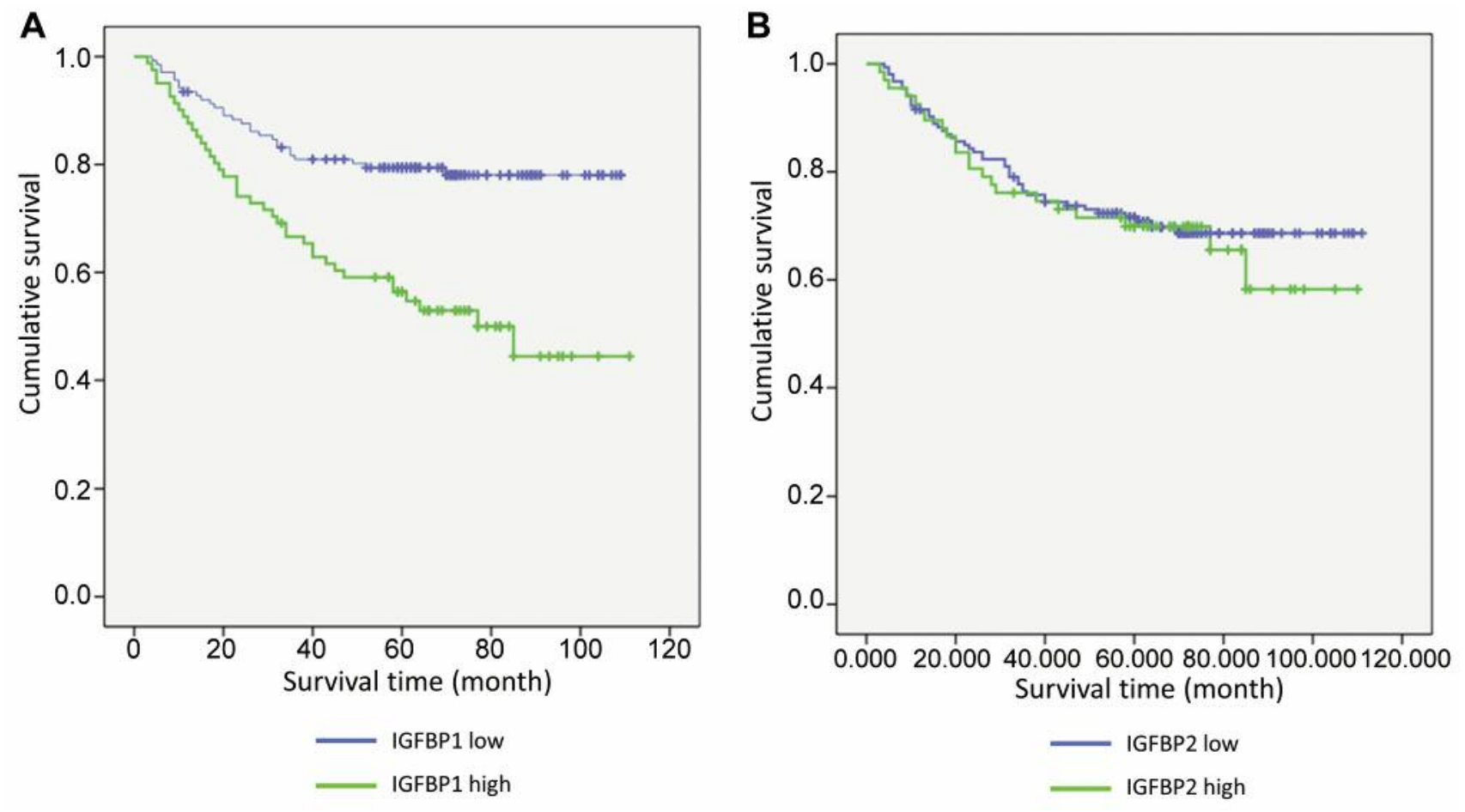

Figure 3. Kaplan-Meier curves of the disease-specific survival (DSS) of patients with expression of IGFBP1 (A) or IGFBP2 (B).

A

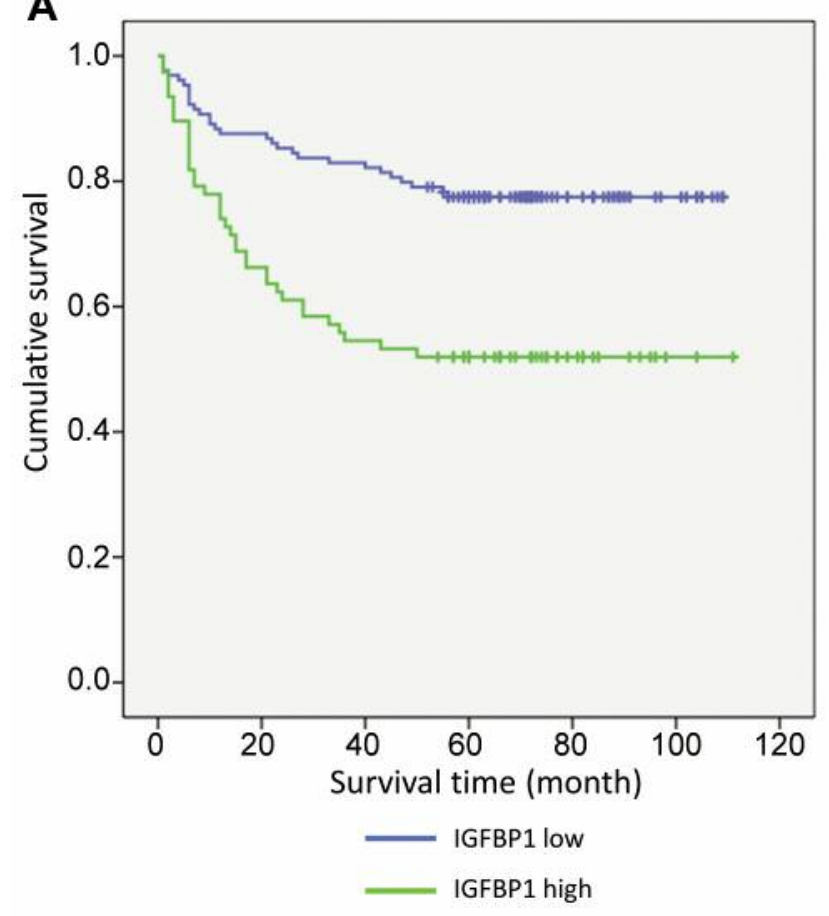

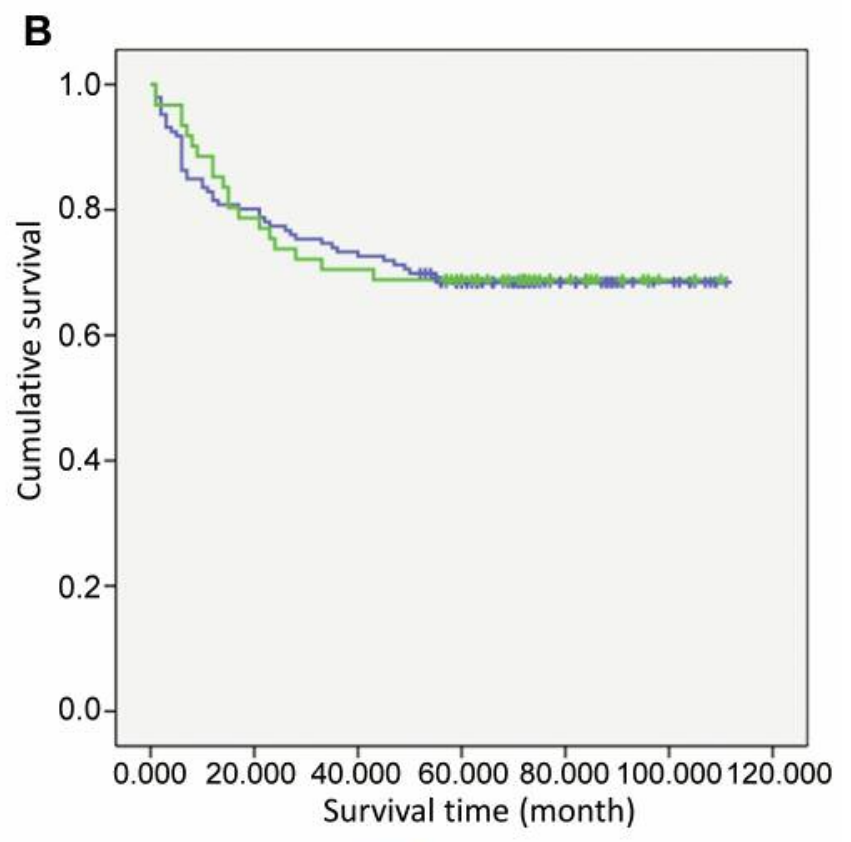

IGFBP2 low IGFBP2 high

Figure 4. Kaplan-Meier curves of the relapse-free survival (RFS) of patients with expression of IGFBP1 (A) or IGFBP2 (B). 
Table IV. Correlation between clinicopathogical factors and haematogenous metastasis.

\begin{tabular}{|c|c|c|c|c|c|c|c|}
\hline & $\begin{array}{c}\text { Haematogenous } \\
\text { metastasis }(-)\end{array}$ & $\begin{array}{c}\text { Haematogenous } \\
\text { metastasis }(+)\end{array}$ & Proportion & $p$-Value & OR & $95 \% \mathrm{CI}$ & $p$-Value \\
\hline \multicolumn{8}{|l|}{ Age (years) } \\
\hline$\geq 65$ & 107 & 9 & $7.8 \%$ & 0.81 & & & \\
\hline$<65$ & 94 & 9 & $8.7 \%$ & & & & \\
\hline \multicolumn{8}{|l|}{ Gender } \\
\hline Male & 148 & 17 & $10.3 \%$ & 0.05 & 4.5 & $0.5-38.1$ & 0.164 \\
\hline Female & 53 & 1 & $1.9 \%$ & & & & \\
\hline \multicolumn{8}{|l|}{ Lauren Classification } \\
\hline Intestinal & 94 & 10 & $9.6 \%$ & 0.62 & & & \\
\hline Diffuse & 107 & 8 & $7.0 \%$ & & & & \\
\hline \multicolumn{8}{|l|}{ Depth of invasion } \\
\hline $\mathrm{T} 1$ & 85 & 1 & $1.2 \%$ & 0.002 & & & \\
\hline $\mathrm{T} 1, \mathrm{~T} 2, \mathrm{~T} 3$ & 116 & 17 & $12.8 \%$ & & 2.8 & $0.3-24.6$ & 0.361 \\
\hline \multicolumn{8}{|l|}{ LN metastasis } \\
\hline Negative (N0) & 108 & 4 & $3.6 \%$ & 0.013 & & & \\
\hline Positive (N1/2/3) & 93 & 14 & $13.1 \%$ & & 1.2 & $0.3-5.0$ & 0.282 \\
\hline \multicolumn{8}{|l|}{ Lymphatic invasion } \\
\hline Negative & 72 & 1 & $1.4 \%$ & 0.008 & & & \\
\hline Positive & 129 & 17 & $11.6 \%$ & & 3.6 & $0.3-39.4$ & 0.33 \\
\hline \multicolumn{8}{|l|}{ Venous invasion } \\
\hline Negative & 76 & 3 & $3.8 \%$ & 0.12 & & & \\
\hline Positive & 125 & 15 & $10.7 \%$ & & & & \\
\hline \multicolumn{8}{|l|}{ Stage } \\
\hline I & 101 & 3 & $2.9 \%$ & 0.006 & & & \\
\hline II/III/IV & 100 & 15 & $13.0 \%$ & & & & \\
\hline \multicolumn{8}{|l|}{ IGFBP1 expression } \\
\hline Low & 137 & 1 & $0.7 \%$ & $<0.001$ & & & \\
\hline High & 64 & 17 & $21.0 \%$ & & 22.7 & $2.7-188.0$ & 0.004 \\
\hline \multicolumn{8}{|l|}{ IGFBP2 expression } \\
\hline Low & 144 & 9 & $5.9 \%$ & 0.064 & & & \\
\hline High & 57 & 9 & $13.6 \%$ & & 0.9 & $0.3-2.6$ & 0.811 \\
\hline
\end{tabular}

LN: Lymph node; OR: odds ratio; CI: confidential interval.

2 Sasako M, Sakuramoto S, Katai H, Kinoshita T, Furukawa H, Yamaguchi T, Nashimoto A, Fujii M, Nakajima T and Ohashi Y: Five-year outcomes of a randomized phase III trial comparing adjuvant chemotherapy with s-1 versus surgery alone in stage II or III gastric cancer. J Clin Oncol 29(33): 4387-4393, 2011. PMID: 22010012. DOI: 10.1200/JCO.2011.36.5908

3 Nashimoto A, Akazawa K, Isobe Y, Miyashiro I, Katai H, Kodera Y, Tsujitani S, Seto Y, Furukawa H, Oda I, Ono H, Tanabe S and Kaminishi M: Gastric cancer treated in 2002 in Japan: 2009 annual report of the JGCA nationwide registry. Gastric Cancer 16(1): 1-27, 2013. PMID: 22729699. DOI: 10.1007/s10120-012-0163-4

4 Katai H, Ishikawa T, Akazawa K, Isobe Y, Miyashiro I, Oda I, Tsujitani S, Ono H, Tanabe S, Fukagawa T, Nunobe S, Kakeji Y, Nashimoto A and Registration Committee of the Japanese Gastric Cancer A: Five-year survival analysis of surgically resected gastric cancer cases in Japan: A retrospective analysis of more than 100,000 patients from the nationwide registry of the Japanese Gastric Cancer Association (2001-2007). Gastric Cancer 21(1): 144-154, 2018. PMID: 28417260. DOI: 10.1007/ s10120-017-0716-7
5 Pollak M: Insulin and insulin-like growth factor signalling in neoplasia. Nat Rev Cancer 8(12): 915-928, 2008. PMID: 19029 956. DOI: $10.1038 / \mathrm{nrc} 2536$

6 Matsubara J, Yamada Y, Hirashima Y, Takahari D, Okita NT, Kato K, Hamaguchi T, Shirao K, Shimada Y and Shimoda T: Impact of insulin-like growth factor type 1 receptor, epidermal growth factor receptor, and her2 expressions on outcomes of patients with gastric cancer. Clin Cancer Res 14(10): 30223029, 2008. PMID: 18483367. DOI: 10.1158/1078-0432.CCR07-1898

7 Rajaram S, Baylink DJ and Mohan S: Insulin-like growth factorbinding proteins in serum and other biological fluids: Regulation and functions. Endocr Rev 18(6): 801-831, 1997. PMID: 9408744. DOI: 10.1210/edrv.18.6.0321

8 Bach LA: Igf-binding proteins. J Mol Endocrinol 61(1): T11T28, 2018. PMID: 29255001. DOI: 10.1530/JME-17-0254

9 Shi LH, Zhu XQ, Zhao GH, Xia YB and Zhang YS: Expression of insulin-like growth factor binding protein-2 in gastric carcinoma and its relationship with cell proliferation. World $\mathbf{J}$ Gastroenterol 12(39): 6285-6289, 2006. PMID: 17072950. DOI: 10.3748/wjg.v12.i39.6285 
10 Zhang L, Huang W, Chen J, Zhou X, Lu Z and Zhou H: Expression of igfbp2 in gastric carcinoma and relationship with clinicopathologic parameters and cell proliferation. Dig Dis Sci 52(1): 248-253, 2007. PMID: 17171534. DOI: 10.1007/s10620006-9358-z

11 Smith E, Ruszkiewicz AR, Jamieson GG and Drew PA: Igfbp7 is associated with poor prognosis in oesophageal adenocarcinoma and is regulated by promoter DNA methylation. Br J Cancer 110(3): 775-782, 2014. PMID: 24357797. DOI: 10.1038/bjc. 2013.783

12 Sato Y, Inokuchi M, Takagi Y, Otsuki S, Fujimori Y, Yanaka Y, Kobayashi K, Higuchi K, Kojima K and Kawano T: Relationship between expression of igfbp7 and clinicopathological variables in gastric cancer. J Clin Pathol 68(10): 795-801, 2015. PMID: 26043748. DOI: $10.1136 /$ jclinpath-2015-202987

13 Kaaks R, Toniolo P, Akhmedkhanov A, Lukanova A, Biessy C, Dechaud H, Rinaldi S, Zeleniuch-Jacquotte A, Shore RE and Riboli E: Serum c-peptide, insulin-like growth factor (igf)-i, igfbinding proteins, and colorectal cancer risk in women. J Natl Cancer Inst 92(19): 1592-1600, 2000. PMID: 11018095. DOI: 10.1093/jnci/92.19.1592

14 Perks CM, Newcomb PV, Norman MR and Holly JM: Effect of insulin-like growth factor binding protein-1 on integrin signalling and the induction of apoptosis in human breast cancer cells. J Mol Endocrinol 22(2): 141-150, 1999. PMID: 10194517.

15 Dai B, Ruan B, Wu J, Wang J, Shang R, Sun W, Li X, Dou K, Wang D and Li Y: Insulin-like growth factor binding protein-1 inhibits cancer cell invasion and is associated with poor prognosis in hepatocellular carcinoma. Int J Clin Exp Pathol 7(9): 5645-5654, 2014. PMID: 25337205.

16 Luo C, Sun F, Zhu H, Ni Y, Fang J, Liu Y, Shao S, Shen H and $\mathrm{Hu} \mathrm{J}$ : Insulin-like growth factor binding protein-1 (igfbp-1) upregulated by helicobacter pylori and is associated with gastric cancer cells migration. Pathol Res Pract 213(9): 1029-1036, 2017. PMID: 28864349. DOI: 10.1016/j.prp.2017.08.009

17 Firth SM and Baxter RC: Cellular actions of the insulin-like growth factor binding proteins. Endocr Rev 23(6): 824-854, 2002. PMID: 12466191. DOI: 10.1210/er.2001-0033

18 Bach LA: Endothelial cells and the igf system. J Mol Endocrinol 54(1): R1-13, 2015. PMID: 25351818. DOI: 10.1530/JME-140215
19 Chuang YW, Chang WM, Chen KH, Hong CZ, Chang PJ and Hsu HC: Lysophosphatidic acid enhanced the angiogenic capability of human chondrocytes by regulating gi/nf-kbdependent angiogenic factor expression. PLoS One 9(5): e95180, 2014. PMID: 24879414. DOI: 10.1371/journal.pone.0095180

20 Leiper J, Nandi M, Torondel B, Murray-Rust J, Malaki M, O'Hara B, Rossiter S, Anthony S, Madhani M, Selwood D, Smith C, Wojciak-Stothard B, Rudiger A, Stidwill R, McDonald NQ and Vallance P: Disruption of methylarginine metabolism impairs vascular homeostasis. Nat Med 13(2): 198-203, 2007. PMID: 17273169. DOI: 10.1038/nm1543

21 Leu JI and George DL: Hepatic igfbp1 is a prosurvival factor that binds to bak, protects the liver from apoptosis, and antagonizes the proapoptotic actions of p53 at mitochondria. Genes Dev 21(23): 3095-3109, 2007. PMID: 18056423. DOI: $10.1101 / \operatorname{gad} .1567107$

22 Mehrian-Shai R, Chen CD, Shi T, Horvath S, Nelson SF, Reichardt JK and Sawyers CL: Insulin growth factor-binding protein 2 is a candidate biomarker for pten status and pi3k/akt pathway activation in glioblastoma and prostate cancer. Proc Natl Acad Sci USA 104(13): 5563-5568, 2007. PMID: 17372210. DOI: 10.1073/pnas.0609139104

23 Holmes KM, Annala M, Chua CY, Dunlap SM, Liu Y, Hugen N, Moore LM, Cogdell D, Hu L, Nykter M, Hess K, Fuller GN and Zhang W: Insulin-like growth factor-binding protein 2-driven glioma progression is prevented by blocking a clinically significant integrin, integrin-linked kinase, and nf-kappab network. Proc Natl Acad Sci USA 109(9): 3475-3480, 2012. PMID: 22345562. DOI: 10.1073/pnas.1120375109

24 Russo VC, Azar WJ, Yau SW, Sabin MA and Werther GA: Igfbp-2: The dark horse in metabolism and cancer. Cytokine Growth Factor Rev 26(3): 329-346, 2015. PMID: 25544066. DOI: $10.1016 /$ j.cytogfr.2014.12.001

Received March 19, 2019

Revised May 15, 2019

Accepted May 16, 2019 